\title{
Psychological Issues Interfere with Recovery in Patients with Burn
}

\author{
Tahira Hafeez* and Farrukh Aslam Khalid
}

Jinnah Burn\& Reconstructive Surgery Centre, Jinnah Hospital Lahore Pakistan.

\section{ABSTRACT}

A 20 year old female presented with $32 \%$ burn having premorbid psychiatric conditions. She was having history of conversion disorder which complicated her recovery as she developed contracture and stiffness in her limbs which were not burnt, whenever she was asked to mobilize herself she started shouting and crying and her behavior did not let her family to make her exercise. On her readmission she was presented with graft lost from her chest and neck in addition to that contractures on knees and leg. The patient remained admitted for 65 days and as her psychological problem worsen her condition so at first stage her conversional issues were managed by applying extinction technique. Family was also counseled to with draw the whole secondary gains like undue attention and support. It took 30 days to make her mobilized and complied with treatment. She was grafted on neck, arm and chest and on her discharge she was completely mobilized and her grafts were stuck.

So the study concludes that psychological problems complicate the recovery in patients with burn, so for the better recovery, Attending psychological issues first particularly issues like Conversion.

Keywords: Conversion: Psychological Condition, Grafting: Surgical Procedure, La Belle Indifference: Feature of Conversion Disorder.

\section{Introduction}

The present case history discusses about a female victim of burn, who got burnt accidently but her psychological issues, Conversion, complicated her recovery.

Conversion is also known as functional neurological symptom disorder ${ }^{1}$. Conversion is a psychological disorder, belongs to somatoform cluster of disorders, in this disorder individual usually turns his psychological problems into physical symptoms which can manifest as sudden blindness, paralysis of any limb, mutism, patient can become unconscious for minutes or hours but in these fits no injury occurs to the patients whereas patients gets injuries with Epileptic fits ${ }^{2}$ Although patient does not do it on conscious level but when the patient cannot handle stress appropriately his stress turns into physiological symptoms. Usually patients with Conversion do have secondary gains which are like attention seeking and diversion from the actual issues ${ }^{3}$. Conversion disorder may present at any age but is rare in children younger than 10 years or in the elderly. Studies suggest a peak onset in the mid-to-late $30 \mathrm{~s}^{4}$. The reason of functional neurologic disorders is unidentified. The illness may be elicited by a neurological disorder or by a response to stress or psychological or physical trauma, but that's not at all times the case. Functional neurologic disorders are associated to how the brain functions, rather than injury to the brain's structure (such as from a stroke, multiple sclerosis, infection or injury). Conversion can occur with other medical conditions which can hinder the recovery with that medical condition ${ }^{5}$.

The present study aims to high light the importance of attending psychological issues for better response of treatment in burn patients.

\section{Case Report}

FK 20 years old married female, mother to two children, was borne in a middle class family her father was a laborer and her mother was house wife. There were 8 members in family client, her 4 siblings, parents and her grandmother (who was bed ridden due to her left side paralysis). She was $2^{\text {nd }}$ among her five siblings. She achieved her milestone at appropriate age and started school at the age of 5years. She just completed her middle education and did not continue her education. Her parents reported that since child hood she was not easy going child as she was stubborn and attention seeking. Her conversional fits started at the age of 12 years. She used to be unconscious whenever she was not given what she wanted. Her fits prolonged for hours and she never got any injury due to her fits. Her fits continued even after her marriage. And her attention seeking and conversional behavior brought her to her current situation.

FK had history of accidental burn while cleaning her kitchen, her foot slipped and fell on the stove, meanwhile her shirt caught fire and her upper limbs, Right Arm, chest, abdomen and neck got burnt. With $32 \%$ total burn surface area she was presented in district headquarter hospital of 
Sailkot where she was initially managed and referred to Jinnah Burn and Reconstructive surgery center Lahore. During her stay for 35 days at hospital grafting of wounds was done. She had been given extensive physiotherapy and psychological support, on her discharge she was full mobilized, managing herself independently, walking, stable psychologically and her $80 \%$ wounds were healed. Patient was advised for dressing on every week but she did not return for follow up.

After five months of discharge patient again presented to Jinnah hospital emergency and from there she was referred to Jinnah Burn \& Reconstructive Surgery Centre Jinnah hospital Lahore. On her presentation she lost her neck graft and developed neck contracture. Moreover her knee joints got stiff albeit she was not having any wound on knees nor her legs got burnt, along with that her right arm and hand also got immobile and stiff.

As being married the patient was living with her in- laws and primarily her husband and mother in law were taking care of her. As she is mother of two girls her younger daughter was just of nine months but not been breast fed due her mother's injury and sine accident her daughters were been taken care by her parents. On the report of her husband during her stay at home she all the time used to lay down and she left walking and managing herself which she was doing in hospital, moreover she did not let anybody to touch her arm and neck for exercise. In addition to this she refused to walk as she used to complain of pain in leg and if her husband or mother in law tried to help she started abusing them and got unconscious, as a result her right leg got stiffed.

At present the patient was presented as bed ridden she could not walk on her own though her leg were not having any wound neither they got burnt. On exploration her family reported that her stubborn, conversional and attention seeking behavior was the reason of this current situation as she became unconscious when someone asked her to walk or started giving emotional statements and screaming. More over family's ignorance reinforced her diseased behavior and as a result she not only lost her neck and chest grafting but also got immobile.

During her stay on her readmission she tried to apply all the learnt behaviors to interfere her recovery as whenever physiotherapist came to make her exercise she started shouting that she has pain and got unconscious or if stood up with the support she fell down by saying that she cannot move as her legs have black magic effect and sometimes she got unconscious, while screaming, getting unconscious her face remained flat or calm which is a clear feature, called (la belle indifference) ${ }^{6}$ of conversion as during conversional attacks patients remains calm and peaceful while whole family gets panic.

Assessment: Patient personal account and family history shows that the patient used to get faint whenever asked to walk or she used to say that her leg is immobile though there was no burn on legs, by doing so, she tried to divert family from actual task and on the other hand family used to get worried about the patient condition

Patients current symptoms are non- compliance to treatment, shouting, getting unconscious whenever asked for walk and immobile leg when the leg has no wound but being bed ridden developed knee contracture .she is having all these symptoms since she got discharged from hospital after her first stay. Her symptoms indicate that she has conversional problems ${ }^{7}$. Patient's history shows that FK is having psychological problems since she was 12 year old. It was started when she asked her mother to let her go to funfair at school and her mother did not allow and she got unconscious and fell down on floor but did not get any injury. Her mother took her to the hospital and these episodes remained continue till this day. Usually people with conversion have a diseased role model in the family in this following case Fk's grandmother was bed ridden ${ }^{8}$. All the labs, routine tests were normal ${ }^{9}$.

\begin{tabular}{|l|l|}
\hline \multicolumn{2}{|c|}{ Factors affecting the problem behavior } \\
$\begin{array}{l}\text { Perpetuating } \\
\text { Factors }\end{array}$ & $\begin{array}{l}\text { Pre morbid personality of Patient } \\
\text { Attention seeking behavior } \\
\text { Having history of conversional } \\
\text { symptoms since the age } 12 .\end{array}$ \\
\hline Contributing factors & $\begin{array}{l}\text { Family attitude } \\
\text { Poor compliance to the instruction }\end{array}$ \\
\hline Maintaining factors & $\begin{array}{l}\text { Accidental burn injury } \\
\text { False believes like black magic } \\
\text { Poor skills of interpersonal } \\
\text { relationships }\end{array}$ \\
\hline
\end{tabular}

\section{Intervention}

For 30 days she had been under extensive psychological treatment as this had been decided with team that her surgical treatment like grafting would be done once she gets over her psychological problem and complies with the treatment. Techniques of Behavioral therapy like (extinctions, flooding, and fading ) were applied and along with counseling of family and patient ${ }^{10}$.

\section{Discussion}

Conversion is such psychological problems in which individual turns his psychological symptoms into his physical symptoms and patient faces this problem when he is not capable of handling stressful situation and all this happens at unconscious level ${ }^{3}$. 
Tables: Pre and post treatment ratings on 0 - 10 point scale given by the family.

\begin{tabular}{|c|c|c|}
\hline Problems & Pre & Post \\
\hline Fits & 8 & 0 \\
\hline Leg immobility & 9 & 1 \\
\hline screaming & 7 & 1 \\
\hline Compliance to treatment & 10 & 3 \\
\hline Hand immobility & 9 & 2 \\
\hline Verbal abuse & 7 & 1 \\
\hline
\end{tabular}

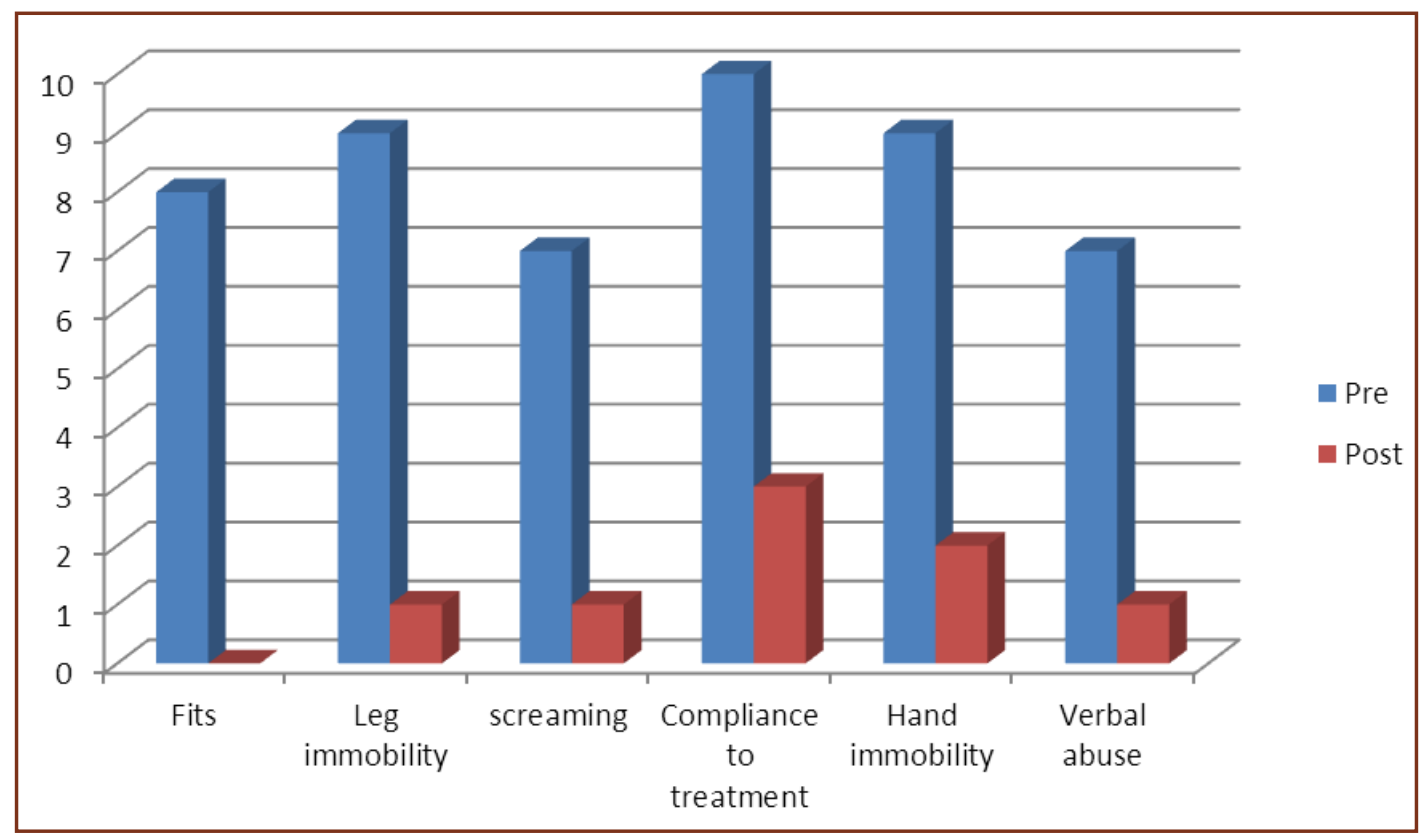

The graph shows a marked decrease in symptoms.

FK was presented with the compliant of loss of graft from her burnt body surface neck and chest, Stiffness in leg which was not burnt. She Was getting unconscious whenever asked to exercise8. Her present symptoms and history led to the diagnosis of conversion?

Premorbid psychological conditions in burns injuries complicate the recovery ${ }^{5}$ as in the following case patient conversional symptoms not only delayed the recovery but also compromised the quality of recovery.

Although burn is continuous burden for the patient and patient may develop multiple psychological issues as coping with burn is a challenge so timely and at every stage psychological intervention is important to speed up the recovery ${ }^{1}$. FK faced the complications caused by her psychological (conversion) problems but an intensive psychological intervention and support (behavior therapy techniques extinctions, flooding, and fading $)^{10}$ decreased her symptoms, which led successful surgery and grafting with speedy recovery.

\section{Conclusion}

The case study suggested that looking after psychological issues of patient with burn are needed to be attended carefully, because burn itself is a trauma to handle with and if the patient is already having premorbid psychological condition, recovery with burn gets difficulty. Moreover timly and right psychological intervention can speed up the recovery.

\section{Acknowledgements}

I am really thank you to the Executive Director, Prof; Dr Moazam Tarar Jinnah Burn \& Reconstructive Surgery Centre for allowing me to share the case study.

\section{Reference}

1. Omasson K, Kent D, Coryell W. Somatization and conversion disorders: comorbidity and demographics at presentation. Acta Psychiatr Scand. 1991; 84 :288-93

2. Conversion and somatic symptom disorders. 2015. Retrieved 11 April, 2018 
3. Akagi H, House A O. The epidemiology of hysterical conversion". In P. Halligan, C. Bass, J. Marshall (Eds.) Hysterical Conversion: clinical and theoretical perspectives . 2001. 73-87.

4. Carson AJ, Ringbauer B, Stone J, McKenzie L, Warlow C, Sharpe M. Do medically unexplained symptoms matter? A prospective cohort study of 300 new referrals to neurology outpatient clinics. J. Neurol. Neurosurg. Psychiatry. 2000; $68: 207-10$.

5. Shelley A Wiechman, David R Patterson. Psychologial aspact of burn injuries. BMJ. 2004; 329: 391-393.

6. Stone J, Smyth R, Carson A, Warlow C, Sharpe M. La belle indifférence in conversion symptoms and hysteria: systematic review”. Br J Psychiatry. 2006; 188: 204-9.
7. Diagnostic and Statistical Manual of Mental Disorders, fifth Edition, American Psychiatric Association

8. Conversion and somatic symptom disorders". Retrieved 25 November 2015.

9. Stone J, Carson A, Sharpe M. Functional symptoms and signs in neurology: assessment and diagnosis". J. Neurol. Neurosurg. Psychiatry. 2005; 1: 2-12.

10. Ruddy R, House A. Psychosocial interventions for conversion disorder .Cochrane Database Syst. 2005. Rev (4).

11. Patterson DR, Ford GR. Burn injuries. In: Frank RG, Elliott TT, eds. Handbook of rehabilitation psychology. Washington DC: American Psychological Association, 2000: $145-62$

*Corresponding author:

Tahira Hafeez, Clinical Psychologist, Jinnah Burn \& Reconstructive Surgery Centre Jinnah hospital Lahore, Pakistan 54000 Phone: +91 0923224597897

Email: Tahirarubab_cp@hotmail.com

Financial or other Competing Interests: None. 